\title{
Alloy substitution in a critical raw materials perspective
}

\author{
P. Ferro, F. Bonollo \\ University of Padova, Italy \\ paolo.ferro@unipd.it, bttps://orcid.org/0000-0001-8682-3486 \\ franco.bonollo@unipd.it, https://orcid.org/0000-0002-7196-2886
}

S.A. Cruz

Eurecat, Centre Tecnològic de Catalunya, Unitat de Materials Metàl-lics i Ceràmics, Av. Universitat Autònoma, Spain sylvia.cruz@eurecat.org

\begin{abstract}
Since many years, the European Community has been monitoring some raw materials because of their high importance to the European Union economy and their high supply risk. Such raw materials, classified as critical, form a strong industrial base, producing a lot of goods and applications used in everyday life and modern technologies. Many critical raw materials are used as alloying elements and their high supply risk may constitute a serious problem for the future world economy and technological progress. Mitigating actions are therefore needed such as recycling, material efficiency improvements and, when possible, material substitution. In the present work, a systematic approach for alloy substitution and/or optimization in a critical raw materials perspective is developed. The method is illustrated with an example.
\end{abstract}

KEYwORDS. Raw material; Criticality index; Materials selection; Metals and alloys; Alloy substitution.

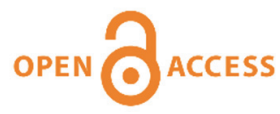

Citation: Ferro, P., Bonollo, F., Cruz, S.A., Alloy Substitution in a Critical Raw Materials Perspective, Frattura ed Integrità Strutturale, 51 (2020) 81-91.

Received: 20.08 .2019

Accepted: 02.11.2019

Published: 01.01.2020

Copyright: (C) 2020 This is an open access article under the terms of the CC-BY 4.0, which permits unrestricted use, distribution, and reproduction in any medium, provided the original author and source are credited.

\section{INTRODUCTION}

$\mathrm{R}$ aw materials are crucial to World's economy. They are essential to securing a transition to green energy technologies, to securing growth and sustainable consumption and to securing access to clean and efficient consumer technologies. Therefore, monitoring the availability of raw materials is of growing interest within the European Union (EU) and across the globe. In this scenario the EU identified a series of raw materials that are critical because they are highly important to the EU economy and, at the same time, they suffer of a high supply risk. For this reason, critical raw materials (CRMs) are subjected to a regular review and update. The last updated report about CRMs [1] identified as critical: Antimony, Beryllium, Borates, Cobalt, Coking Coal, Fluorspar, Gallium, Germanium, Indium, Magnesium, Natural Graphite, Niobium, Phosphate Rock, Silicon Metal, Tungsten, Platinum Group Metals, Light Rare 
Earths and Heavy Rare Earths, Baryte, Bismuth, Hafnium, Helium, Natural Rubber, Phosphorus, Scandium, Tantalum, and Vanadium. The CRMs list is updated every three years.

As it can be observed from the above mentioned 'black list', CRMs are linked to clean technologies. They are irreplaceable in solar panels, wind turbines, electric vehicles, and energy-efficient lighting.

Unfortunately, the criticality assessment related to raw materials is a very difficult task and there is not a recognized method to reach that goal in literature [2,3]. For example, in a recent paper, Hofmann et al. [4] showed that material scientists seem frequently not concerned with the criticality of raw materials so that they suggested to advance the implementation of the concept of materials criticality in materials research and development. An excellent review of the criticality concept, as well as the methodologies used in its assessment, was presented by Frenzel et al. [5]. In that work, the authors also discussed a number of risks present in global raw materials markets that are not captured by most criticality assessments and, finally, they proposed measures for the alleviation of such risks.

In another recent paper, Tkaczyk et al. [6] present a multi-faceted and multi-national review of the essentials for the critical raw materials, $\mathrm{Co}, \mathrm{Nb}, \mathrm{W}$, and rare earth elements (REEs).

Such raw materials are relevant for emerging technologies and will thus continue to be of increasing major economic importance. That paper deals with also a 'sustainability evaluation' for each element, including essential data about markets, applications and recycling. Possibilities for substitution is finally summarized and analyzed.

In recent studies, the European Commission's Joint Research Centre (JRC) showed that several green technologies could be at risk because of potential supply risks of certain metals [7-9]. In particular, electric vehicles are of particular criticism because their dependence on critical REEs used in $\mathrm{NdFeB}$ permanent magnets (PM). Because of its high energy density, $\mathrm{NdFeB}$ is expected to be used also in high-tech applications and energy-related devices such as generators in wind turbines [10]. For these reasons, the global demand for REEs is likely to be increasing in the coming years [10-13], despite they are evaluated as 'critical materials' [14-19]. Among the 'mitigating strategies' aimed to face this issue, both recycling and substitution are considered in literature. For instance, substitution was found more feasible in cases where it takes place at the product, component or technology level rather than the element level [20-22]. Many works in literature confirm the substitution as a good method to face the increasing challenge of CRMs supply risk [23-26]. The research framework programs (e.g. FP7 and H2020) provides financial support to relevant projects related to substitution of critical raw materials. Gkanas et al. [27] defined four advantages linked to CRMs substitution: flexibility in materials supply, cost saving, weaken monopoly power of suppliers and environmental benefits. In 2012, the European Parliament observed that 'the majority of substitutes are currently in the research and development stage and market-ready solutions are rarely available' [28]. Therefore, the substitution concept needs to broaden its scope to include, for instance, product design, changes to process, higher material efficiency and product replacement by new technology [29].

In this scenario, Pavel et al. studied the possibility to substitute rare earths used both in electric road transport applications [30] and wind turbines [31]. They firstly showed how, despite the benefits of climate change mitigation and from potential fuel savings, several barriers could hinder the widespread adoption of electric vehicles because a potential supply disruption of critical rare earths for magnet-based electric traction motors. They demonstrated how the potential supply risks associated with rare earths for electric road transport applications cannot be easily mitigated as there are no effective substitutes for the rare earths used in permanent magnets. The general feeling is that more effort is needed to develop new solutions and to search for even better alternatives.

In another work, Rademaker et al. [32] showed that in the brief period waste flows from permanent magnets will remain small relative to the rapidly growing global rare earth elements demand. Therefore, during the next decade, recycling is unlikely to substantially contribute to global REE supply security. On the other hand, in the long term, waste flows will increase sharply and will meet a substantial part of the total demand for these metals. Future REE recycling efforts should, therefore, focus on the development of recycling technology and infrastructure.

Perez et al. [33] provides an overview of the present status and outlook on technologies used to recover critical metals from solution, including precipitation, reduction, ion exchange, solvent extraction, electrochemical methods and adsorption onto novel, sustainable materials. They finally suggested key directions to tackle existing challenges in the field of resource recovery and improve the sustainability of future material cycling.

Despite the different works present in literature aimed to assess the raw materials criticality and suggest mitigating actions such as recycling and substitution, methods aimed to help the designer to play out the necessary 'mitigating actions' required to reduce the criticality of industrial products are not yet developed. Literature studies are mainly focused on REEs substitution with particular reference to specific applications [34] while a systematic methodology for a generic critical material substitution in design is still absent. In the following, an overall indicator for raw material criticality assessment is first proposed. A systematic procedure for alloy substitution in a CRMs perspective is then developed and illustrated with an example. 


\section{CRITICALITIES ASSESSMENT}

I $\mathrm{n}$ literature, the criticality issues linked to each raw material are quantified by a series of indexes such as the abundance risk, the sourcing and geopolitical risk, the environmental country risk, the supply risk, the economic importance and finally, the end of life recycling input rate

In order to use such indicators in design, it would be necessary to aggregate the above-mentioned indexes in an overall general indicator for each critical raw material to reach this goal. One possibility should take the normalized value of each index in order to remove the units and reduce them to a common scale (0-10, for instance). Then, they may eventually be weighted to reflect the perceived seriousness of each criticality, and finally, the weighted, normalized measures should be summed or averaged to give the indicator.

The Abundance Risk Level (ARL) of the CRM ' $\mathrm{i}$ ' is associated to the value of the 'Abundance in the Earth's crust (AEC) [ppm]' by the following proposed relation:

$$
A R L_{i}=10-\left[10+\log \left(\frac{A E C_{C R M_{i}}}{A E C_{C R M_{\max }}}\right)\right]
$$

where AEC $_{\text {CRMi }}$ stays for the amount in the Earth's crust of the CRM ' $\mathrm{i}$ ' (measured in ppm) and AEC CRMmax $_{\text {in }}$ is the maximum value found in the CRMs list.

The Sourcing and Geopolitical Risk (SGR) index indicates the supply disruption risk due to political factors, based on the countries in which the element is produced (e.g. in terms of political stability and control of corruption) and the concentration of worldwide production. A higher value means a higher risk.

According to EU Report of the Ad-hoc Working Group on defining critical raw materials (2010, [35]), the sourcing and geopolitical risk for an element ' $i$ ' is a modified and scaled Herfindahl-Hirschmann Index, calculated as (Eqn. 2):

$$
H H I_{i}^{W G I}=\sum_{c}\left(S_{i c}\right)^{2} W G I_{c}
$$

where $W_{G I}$ is the World Bank's "Worldwide Governance Indicator" for the producing country ' $c$ ' and $S_{\text {ic }}$ is the percentage (\%) of worldwide production of the raw material ' $i$ ' within country ' $c$ ' [35].

The World Bank "Worldwide Governance Indicator" measures the political and economic stability of producing countries. In this context it is useful to remember that the Herfindahl-Hirschmann Index (HHI) gives an indication of the level of concentration of production of a raw material within any one country, in terms of its annual worldwide production. In economic terms, it is used to gauge the risk of monopolistic production within the supply chain of the material under consideration. The higher its value, the higher the risk. In this work the SGR index of the CRM ' $i$ ' is normalized and scaled as follows:

$$
S G R_{i}=\frac{H H_{i}^{W G I}}{H H_{\max }^{W G I}} \cdot 10
$$

where HHIWGI ${ }_{\text {max }}$ is the maximum value reached by the index HHIWGI in the CRMs list.

The Environmental country risk (ECR) indicates the risk that worldwide supply of an element may be restricted in future as a result of environmental protection measures taken by any of its producing countries. A higher value means a greater risk that environmental legislation may restrict supply in the future. It is quantified, for an element ' $i$ ', by the following equation:

$$
E C R_{i}=\frac{H H I_{i}^{E P I}}{H H I_{\max }^{E P I}} \cdot 10
$$

where, 


$$
H H I_{i}^{E P I}=\sum_{c}\left(S_{i c}\right)^{2}\left(10-\frac{E P I_{c}}{10}\right)
$$

and $\mathrm{HHI}^{\mathrm{EPI}}{ }_{\text {max }}$ stays for the maximum value reached by the index $\mathrm{HHI}^{\mathrm{EPI}} \mathrm{i}_{\mathrm{i}}$ in the $\mathrm{CRMs}$ list.

$\mathrm{EPI}_{\mathrm{c}}$ is the Environmental Performance Index calculated by Yale University, for the producing country 'c' [35]. The Environmental Performance Index (EPI) is a method of quantifying and numerically marking the environmental performance of a state's policies [36]. The greater the EPIc indexes, the lower the risk of supply disruption induced by environmental legislation.

The Supply Risk (SR) indicator quantifies the inadequate supply of a raw material to meet industrial demand. It is calculated by taking into account estimation of how stable the producing countries are (considering the level of concentration of raw material producing countries), the extent to which a raw material 'i' may be substituted, and, finally, the extent to which raw material needs are recycled. The formula for the calculation of the SR index for the element ' $\mathrm{i}$ ' is given by equation (6) [5]:

$$
S R_{i}=g_{i}\left(1-f_{i}\right) H H I_{i}^{W G I}
$$

where $g_{i}$ is the raw material substitutability (defined in equation (7)) and $f_{i}$ is the recycling rate that is the ratio of recycling from old scrap to European consumption.

The substitutability, g, represents the possibility of substituting the raw material ' $\mathrm{i}$ ' and it is calculated as a weighted average over the end-uses/sectors, as follows [5]:

$$
g_{i}=\sum_{s} A_{s} g_{s}
$$

where $A_{s}$ is the share of material consumption in a given end-use sector (s) and the $g_{s}$ value may be zero if the raw material (RM) is easily and completely substitutable at no additional cost, 0.3 if the RM is substitutable at low cost, 0.7 if the RM is substitutable at high cost (and/or loss of performance) and finally 1.0 if the RM is not substitutable. Thus, the higher $g_{i}$, the lower the substitutability. The supply risk is increased if the producing countries are unstable and provide a high share in the world production, because the substitutability is low ( $g_{i}$ is high), and because the recycled rate is low ( 1 $\mathrm{f}_{\mathrm{i}}$ ) is high). In this work, the normalized and scaled SR indicator (NSR) is used:

$$
N S R_{i}=\frac{S R_{i}}{S R_{\max }} \cdot 10
$$

where $\mathrm{SR}_{\max }$ stays for the maximum value reached by the index $\mathrm{SR}_{\mathrm{i}}$ in the CRMs list.

The importance for the economy of a raw material is measured by breaking down its main uses and attributing to each of them the value added of the economic sector that has this raw material as input [5]. The economic importance of a raw material ' $\mathrm{i}$ ' $\left(\mathrm{EI}_{\mathrm{i}}\right)$, is calculated as the weighted sum of the individual megasectors (expressed as gross value added), divided by the European gross domestic product (GDP) (Eqn. 9) [35,37]:

$$
E I_{i}=\frac{1}{G D P_{i}} \sum_{s} A_{s} Q_{s}
$$

In Eqn. (9), As is the share of consumption of a RM in a given end-use sector, s, while Qs is the economic importance of the sector, s, that requires that raw material and it is measured by its value-added. The values for economic importance of each material were scaled to fit in the range from 0 to 10, with higher scores indicating higher economic importance. In the present work, the normalized and scaled EI indicator (NEI) is defined as follows:

$$
N E I_{i}=\frac{E I_{i}}{E I_{\max }} \cdot 10
$$

where $\mathrm{EI}_{\max }$ stays for the maximum value reached by the indicator $\mathrm{EI}_{\mathrm{i}}$ in the CRMs list. 
Finally, The End of Life Recycling Input Rate (EOL-RIR) is 'the input of secondary material to the EU from old scrap to the total input of material (primary and secondary)'. In the EC criticality assessments (EC 2011, 2014), recycling rates and EOL-RIR (\%) refer only to functional recycling. Functional recycling is 'the portion of EOL recycling in which the material in a discarded product is separated and sorted to obtain recyclates'. Recyclates obtained by functional recycling are used for the same functions and applications as when obtained from primary sources; as opposed to recyclates generated from non-functional recycling which substitute other raw materials, and therefore do not contribute directly to the total supply of the initial raw material. In the present work, in order to assess the overall criticality index for each CRM, the EOL-RIR index is substituted by the recycling drawback index (RDI) defined as follows:

$$
R D I_{i}=10-\frac{E O L-R I R_{i}}{E O L-R I R_{\max }} \cdot 10
$$

\section{RAW MATERIALS CRITICALITY INDICATOR (CI CRM $_{\text {) }}$}

7 he criticality indicator for the $\mathrm{CRM}$ 'i' $\left(\mathrm{CI}_{\mathrm{CRMi}}\right)$ is obtained by averaging the above-defined, scaled (0-10) and weighted criticalities indexes values (Eqn. (12)):

$$
C I_{C R M_{i}}=\left(k_{A R L} A R L_{i}+k_{S G R} S G R_{i}+k_{E C R} E C R_{i}+k_{N S R} N S R_{i}+k_{N E I} N E I_{i}+k_{R D I} R D I_{i}\right) / 6
$$

In Eqn. (12) $\mathrm{k}$ is a non-dimensional coefficient which value is in between 0 and 1 , according to the seriousness of the corresponding criticality aspect. When all $\mathrm{k}$ values are set equal to 1 in Eqn. (12), equal seriousness is perceived for all the criticality aspects. The values of the criticality index in Eqn. (12) are calculated by using data taken from the literature [38].

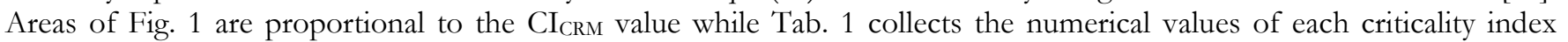
obtained. It is observed (Fig. 1) that the high seriousness of the European Union dependence from rare earths is quantified by the highest values of their criticality indicator.

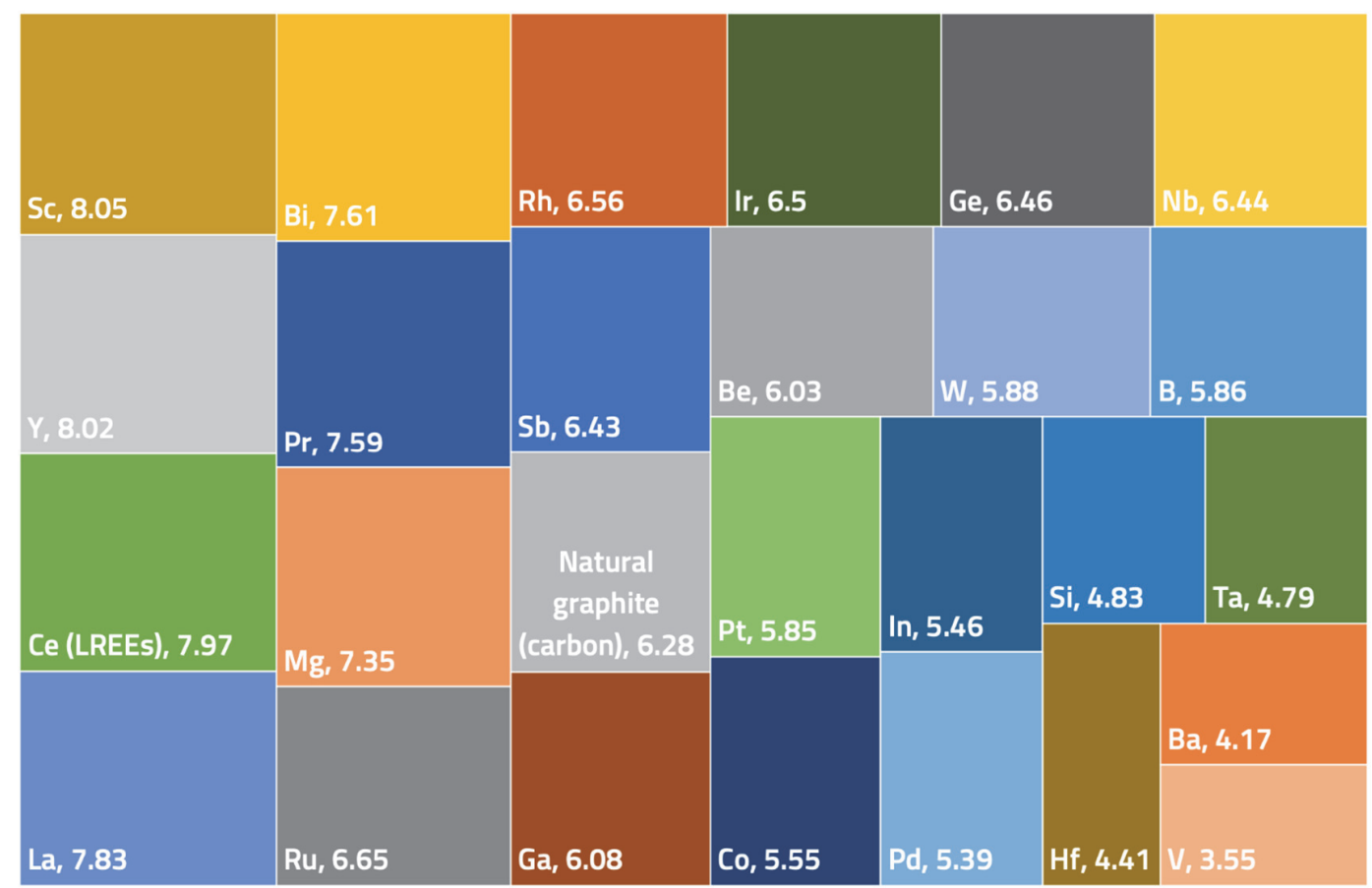

Figure 1: Criticality grade of different CRMs measured by the RM Criticality Indicator ( $k=1$ for all the indexes). 


\begin{tabular}{|c|c|c|c|c|c|c|c|}
\hline CRM & ARL & SGR & ECR & NSR & NEI & RDI & $C I_{C R M}$ \\
\hline $\mathrm{Sb}$ & 6.15 & 6.46 & 7.68 & 8.78 & 5.89 & 3.64 & 6.43 \\
\hline $\mathrm{Ba}$ & 2.82 & 2.59 & 2.62 & 3.27 & 3.97 & 9.77 & 4.17 \\
\hline $\mathrm{Be}$ & 5.00 & 4.49 & 6.43 & 4.90 & 5.34 & 10.00 & 6.03 \\
\hline $\mathrm{Bi}$ & 7.52 & 7.18 & 8.52 & 7.76 & 4.93 & 9.77 & 7.61 \\
\hline B & 4.45 & 5.04 & 5.31 & 6.12 & 4.25 & 10.00 & 5.86 \\
\hline Ce (LREEs) & 3.63 & 10.00 & 9.49 & 10.00 & 4.93 & 9.77 & 7.97 \\
\hline $\mathrm{Co}$ & 4.05 & 4.20 & 3.94 & 3.27 & 7.81 & 10.00 & 5.55 \\
\hline $\mathrm{F}$ & 2.68 & - & - & 2.65 & 5.75 & 9.77 & - \\
\hline $\mathrm{Ga}$ & 4.17 & 6.88 & 8.19 & 2.86 & 4.38 & 10.00 & 6.08 \\
\hline $\mathrm{Ge}$ & 5.27 & 6.97 & 8.33 & 3.88 & 4.79 & 9.55 & 6.46 \\
\hline Hf & 4.97 & 1.31 & 2.02 & 2.65 & 5.75 & 9.77 & 4.41 \\
\hline $\mathrm{He}$ & - & - & - & 3.27 & 3.56 & 9.77 & - \\
\hline In & 6.05 & 3.57 & 3.97 & 4.90 & 4.25 & 10.00 & 5.46 \\
\hline Ir & 8.45 & 5.49 & 6.66 & 5.71 & 5.89 & 6.82 & 6.50 \\
\hline $\mathrm{La}$ & 3.86 & 8.40 & 10.00 & 10.00 & 4.93 & 9.77 & 7.83 \\
\hline $\mathrm{Mg}$ & 1.08 & 7.85 & 9.33 & 8.16 & 9.73 & 7.95 & 7.35 \\
\hline $\begin{array}{l}\text { Natural } \\
\text { graphite } \\
\text { (carbon) }\end{array}$ & 3.15 & 6.98 & 8.33 & 5.92 & 3.97 & 9.32 & 6.28 \\
\hline $\mathrm{Nb}$ & 4.15 & 5.48 & 6.17 & 6.33 & 6.58 & 9.93 & 6.44 \\
\hline $\mathrm{Pd}$ & 7.27 & 3.11 & 3.11 & 3.47 & 7.67 & 7.73 & 5.39 \\
\hline $\mathrm{P}$ & 2.43 & - & - & 2.04 & 6.99 & 6.14 & - \\
\hline $\mathrm{Pt}$ & 7.75 & 3.93 & 4.71 & 4.49 & 6.71 & 7.50 & 5.85 \\
\hline $\operatorname{Pr}$ & 4.49 & 8.40 & 10.00 & 10.00 & 4.93 & 7.73 & 7.59 \\
\hline $\mathrm{Rh}$ & 8.45 & 5.49 & 6.73 & 5.10 & 9.04 & 4.55 & 6.56 \\
\hline $\mathrm{Ru}$ & 8.45 & 5.49 & 6.73 & 6.94 & 4.79 & 7.50 & 6.65 \\
\hline $\mathrm{Sc}$ & 4.11 & 10.00 & 9.49 & 10.00 & 4.93 & 9.77 & 8.05 \\
\hline $\mathrm{Si}$ & 0.00 & 5.37 & 6.36 & 2.04 & 5.21 & 10.00 & 4.83 \\
\hline $\mathrm{Ta}$ & 5.15 & 2.89 & 3.57 & 2.04 & 5.34 & 9.77 & 4.79 \\
\hline W & 5.35 & 7.24 & 8.58 & 3.67 & 10.00 & 0.45 & 5.88 \\
\hline $\mathrm{V}$ & 3.37 & 4.43 & 5.15 & 3.27 & 5.07 & 0.00 & 3.55 \\
\hline Y (HREEs) & 3.93 & 10.00 & 9.49 & 10.00 & 4.93 & 9.77 & 8.02 \\
\hline
\end{tabular}

Table 1: Criticality grade of different CRMs measured by the RM Criticality Indicator ( $k=1$ for all the indexes).

\section{Alloy SUbSTITUTION IN A CRMs PERSPECTIVE}

aterial substitution is one of the mitigating actions aimed to reduce the product criticality in a CRMs perspective. In substituting a material, the designer needs to maintain or increase the component performances while reducing at the same time the criticality issues above described.

By taking into account mechanical components, the main designer's objective is mass reduction, but this is not a limitation of the proposed approach. In the following, the alloy substitution in a pressure vessel new design is considered as an example. When a pressure vessel has to be mobile, its weight becomes important. Aircraft bodies, rocket casings and liquid-natural gas containers are examples; they must be light, and at the same time they must be safe, and that means that they must not fail by fast fracture. If it is assumed that the component is, for simplicity, spherical, of specified radius $\mathrm{R}$, and that the wall thickness, $t$ (the free variable), is small compared with $\mathrm{R}$ (Fig. 2), then the performance equation for the mass $m$ of the pressure vessel is: 


$$
m=4 \pi \mathrm{R}^{2} t \rho
$$

where $\rho$ is the alloy density.

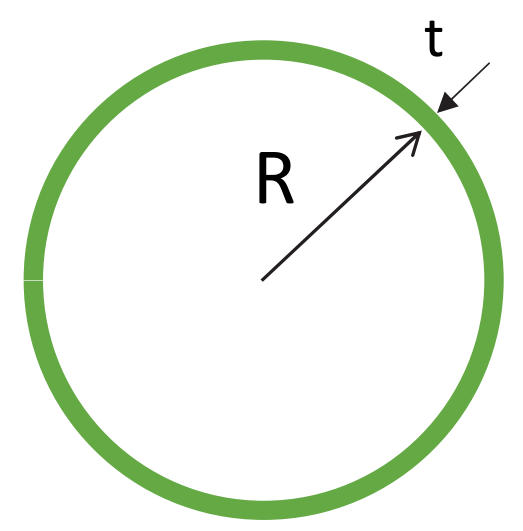

Figure 2: Pressure vessel geometry.

The tensile stress in the wall of a thin-walled pressure vessel is

$$
\sigma=\frac{\Delta p R}{2 t}
$$

where $\Delta \mathrm{p}$, the pressure difference across this wall, is fixed by the design. The constraint is that it should not fail by fast fracture; this requires that the wall-stress be less then $K_{1 c} / \sqrt{\pi c}$, where $K_{1 c}$ is the fracture toughness of the material of which the pressure vessel is made, and $\mathrm{c}$ is the length of the longest crack that the wall might contain.

Equating first the tensile stress (Eqn. 14) to the yield strength $\sigma y$, then to the fracture strength $K_{1 c} / \sqrt{\pi c}$ and substituting for $\mathrm{t}$ in the objective function (Eqn. 13) leads to the performance equation (15) and index (M) laid out below.

$$
\begin{aligned}
& m=2 \pi \Delta p \mathrm{R}^{3}(\pi c)^{1 / 2}\left[\frac{\rho}{K_{1 c}}\right] \\
& M=\frac{\rho}{K_{1 c}}
\end{aligned}
$$

Now, CRMs may be contained, in different amounts, in the alloy composition. Therefore, an alloy criticality index can be defined as follows:

$$
C I_{A}=\sum_{i=1}^{n} C I_{C R M_{i}} \frac{w t^{0}{ }_{C R M_{i}}}{100}
$$

where $\mathrm{n}$ is the number of CRMs in the alloy chemical composition and $\mathrm{wt} \%$ CRMi is the amount of the CRM ' $\mathrm{i}$ ' in the alloy, measured in weight percent. It is observed that the alloy criticality index $\left(\mathrm{CI}_{\mathrm{A}}\right)$ represents an overall criticality value per unit of mass of the alloy. In a CRMs perspective, the objective to be minimized will be the criticality of the designed component (criticality per unit of function). This objective is formulated by multiplying the mass of the component (m) by the alloy criticality index (Eqn. 18) [39]:

$$
m^{*}=m C I_{A}
$$


Since $C I_{A}$ represents an overall criticality value per unit of mass of the alloy, $\mathrm{m}^{*}$ quantifies the criticality of the whole component in a CRMs perspective. This concept can be easily applied to metallic materials. Following the same above described procedure, the new performance equation (19) and index $\left(\mathrm{M}^{*}\right)$ are:

$$
\begin{aligned}
& m^{*}=2 \pi \Delta p R^{3}(\pi c)^{1 / 2}\left[\frac{C I_{A} \rho}{K_{1 c}}\right] \\
& M^{*}=\frac{C I_{A} \rho}{K_{1 c}}
\end{aligned}
$$

$\mathrm{M}$ and $\mathrm{M}^{*}$ are called material indexes, according to Ashby's definition [40].

Pressure vessels are commonly made by low alloy steels, like the UNS K32550 (AMS 6425). For substitution purpose it is thus more convenient to plot the relative values of the materials indexes as shown in Fig. 3, where $\mathrm{M}_{0}$ and $\mathrm{M}_{0}{ }^{*}$ are the material indexes value of the UNS K32550 steel.

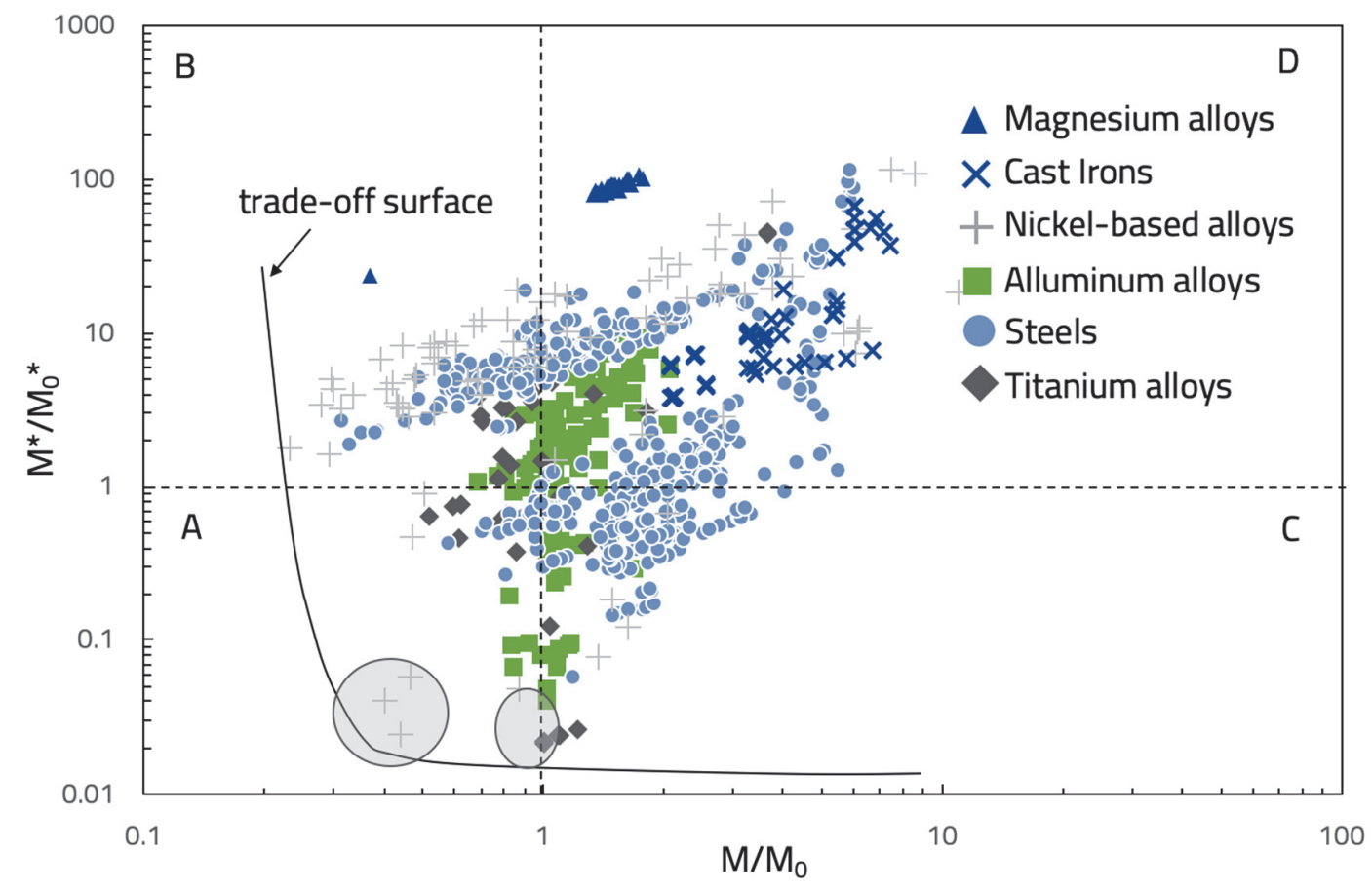

Figure 3: Trade-off plot for the alloy substitution purpose (k coefficient values in Eqn. (12) are set equal to 1).

Each symbol, in Fig. 3, represents a different material. Those which have the characteristic that no other solution exists with lower values of both the performance metrics are said to be non-dominated solutions; the line on which they lie is called optimal trade-off surface.

The point of coordinates (1,1) in Fig. 3 is occupied by the steel to be substituted (UNS K32550). The two straight lines across that point divide the plot in four quadrants named A, B, C and D. Materials lying on the quadrant D are obviously the worst ones since they are heavier and more critical than the reference alloy. Materials that are in the quadrant $\mathrm{C}$, are less critical but heavier than the steel to be substitute; on the contrary, alloys belonging to the quadrant $\mathrm{B}$ are more critical but less heavy. The solutions stay in the quadrant A, where alloys that allow producing both less heavy and less critical pressure vessels are found. In particular, the best solutions must be sought among the non-dominated solutions of the quadrant $\mathrm{A}$. In the example, if the criticality issues are valued much more seriousness than weight reduction, the solution moves to the Titanium grade 1 (EN DIN 3.7025) or the aluminum AA 1080 (strain hardened only). On the other hand, if the criticality issues and weight reduction are valued equally, the Nickel-based alloy UNS N10004 should be considered as a good substitute in a CRMs perspective. 
The analyzed case-study was deliberately simplified in order to demonstrate the potentiality of the method. The obtained solutions must be evaluated by using supporting information and by taking into account other possible constraints defined by the designer such as corrosion resistance, maximum allowed thickness. Despite this, the definition of the criticality indicator and the alloy criticality index allow finding an alloy substitute in a systematic approach. Finally, it is observed that if only one aspect of the raw materials criticality needs to be reduced (say, the recycling issue, RDI), it will be sufficient to set all the other coefficients $\mathrm{k}$ in Eqn. (12) equal to 0.

\section{CONCLUSIONS}

A systematic approach, based on the concept of criticality index, was developed to face the problem of alloy substitution in a critical raw materials perspective. The substitution procedure is based on the definition of the criticality indicator for a generic raw material that takes into account different aspects of the raw materials criticality, quantified by indexes proposed by the European Union. The aggregation of such indexes was obtained by averaging their normalized and weighted values. By using the criticality indicator, the alloy criticality index was then defined. It allows formulating an objective equation that quantifies the criticality per unit of function of a product. That objective equation is finally used for material substitution using the multi-objective strategy proposed by Ashby.

\section{ACKNOWLEDGMENTS}

$\checkmark$ his work is part of the results of the European project called 'Design of Components in a Critical Raw Materials Perspective' (DERMAP, project \# 17205). Authors want to thank EIT RawMaterials for the financial support and all the Project Partners (SWEREA SWEECAST AB, Mondragon University, AGH University, EURECAT, Enginsoft, Fonderie Zanardi) for their contribute to the project development.

\section{REFERENCES}

[1] European Commission (2017). Communication from the commission to the European Parliament, the Council, the European Economic and Social Committee and the Committee of the Regions. Brussels, 13/09/2017 COM(2017) 490 final.

https://ec.europa.eu/transparency/regdoc/rep/1/2017/EN/COM-2017-490-F1-EN-MAIN-PART-1.PDF (accessed on 26 June 2019)

[2] Achzet, B., Helbig, C. (2013). How to evaluate raw material supply risks—an overview. Resources Policy, 38 pp. 435447. DOI: $10.1016 /$ j.resourpol.2013.06.003

[3] Blengini, G.A., Nuss, P., Dewulf, J., Nita, V., Peirò, L.T., Legaz, B.V., Latunussa, C., Mancini,L., Blagoeva, D., Pennington, D., Pellegrini, M., Maercke, A.V., Solar, S., Grohol, M., Ciupagea, C. (2017). EU methodology for critical raw materials assessment: Policy needs and proposed solutions for incremental improvements. Resources Policy, 53, pp. 12-19. DOI: 10.1016/j.resourpol.2017.05.008

[4] Hofmann, M., Hofmann, H., Hageluken, C., Hool, A. (2018). Critical raw materials: A perspective from the materials science community. Sustainable Materials and Technologies, 17, e00074. DOI: 10.1016/j.susmat.2018.e00074

[5] Frenzel, M., Kullik, J., Reuter, M.A., Gutzmer, J. (2017). Raw material 'criticality' — sense or nonsense? Phys. D: Appl. Phys., 50, 123002. DOI: 10.1088/1361-6463/aa5b64

[6] Tkaczyk, A.H., Bartl, A., Amato, A., Lapkovskis, V., Petranikova, M. (2018). Sustainability evaluation of essential critical raw materials: cobalt, niobium, tungsten and rare earth elements. J. Phys. D: Appl. Phys. 2018, 51203001. DOI: 10.1088/1361-6463/aaba99

[7] Moss, R.L., Tzimas, E., Kara, H., Willis, P., Kooroshy, J. Critical metals in strategic energy technologies — assessing rare metals as supply-chain bottlenecks in low-carbon energy technologies, European Commission, Joint Research Centre.

https://publications.europa.eu/en/publication-detail/-/publication/2239d6b7-cda8-4570-a9f0-13ad60ce3f11 (accessed on 09.07.19).

[8] Moss, R.L., Tzimas, E., Kara, H., Willis, P., Kooroshy, J. (2013). The potential risks from metals bottlenecks to the deployment of strategic energy technologies, Energ Policy, 55, pp. 556-564. DOI: 10.1016/j.enpol.2012.12.053 
[9] Moss, R.L., Tzimas, E., Willis, P., Arendorf, J., Espinoza, L.T. Critical metals in the path towards the decarbonisation of the EU energy sector - assessing rare metals as supply-chain bottlenecks in low-carbon energy technologies, European Commission, Joint Research Centre,

https:/ / setis.ec.europa.eu/sites/default/files/reports/JRC-report-Critical-Metals-Energy-Sector.pdf (accessed on 09.07.19).

[10] Stegen, K.S. (2015). Heavy rare earths, permanent magnets, and renewable energies: an imminent crisis, Energ Policy, 79, pp. 1-8. DOI: $10.1016 /$ j.enpol.2014.12.015

[11] European Rare Earths Competency Network (ERECON), Strengthening of the European rare earths supply chain challenges and policy options, http:/ /ec.europa.eu/DocsRoom/documents/10882/attachments/1/translations/en/renditions/native 2015 (accessed on 09.07.19).

[12] Alonso, E., Sherman, A.M., Wallington, T.J., Everson, M.P., Field, F.R., Roth, R., Kirchain, R.E. (2012). Evaluating rare earth element availability: a case with revolutionary demand from clean technologies, Environ. Sci. Technol., 46, pp. 3406-3414. DOI: 10.1021/es203518d

[13] Nansai, K., Nakajima, K., Kagawa, S., Kondo, Y., Suh, S., Shigetomi, Y., Oshita, Y. (2014). Global flow of critical metals necessary for low-carbon technologies: the case of neodymium, cobalt, and platinum, Environ. Sci. Technol., 48, pp. 1391-1400. DOI: 10.1021/es4033452

[14] Massari, S., Ruberti, M. (2013). Rare earth elements as critical raw materials: focus on international markets and future strategies, Resour. Policy, 38, pp. 36-43. DOI: 10.1016/j.resourpol.2012.07.001

[15] Achzet, B., Helbig, C. (2013). How to evaluate raw material supply risk — an overview, Resour. Policy, 38, pp. 435447. DOI: 10.1016/j.resourpol.2013.06.003

[16] Glöser, S., Espinoza, L.T., Gandenberger, C., Faulstich, M. (2015). Raw material criticality in the context of classical risk assessment, Resour. Policy, 44, pp. 35-46. DOI: 10.1016/j.resourpol.2014.12.003

[17] European Commission, Report on critical raw materials for the EU, http:/ / ec.europa.eu/DocsRoom/documents/10010/attachments/1/translations/en/renditions/native 2014 (accessed on 09.07.19)

[18] US Department of Energy, Critical materials strategy, http:/ / energy.gov/sites/prod/files/DOE_CMS2011_FINAL_Full.pdf 2011 (accessed on 09.07.19).

[19] Goe, M., Gaustad, G. (2014). Identifying critical materials for photovoltaic in the US: a multi-metric approach, Appl. Energy, 123, pp. 387-396. DOI: 10.1016/j.apenergy.2014.01.025

[20] Nassar, N.T. (2015). Limitations to elemental substitution as exemplified by the platinum-group metals, Green Chem., 17, pp. 2226-2235. DOI: 10.1039/C4GC02197E

[21] Pavel, C.C., Marmier, A., Tzimas, E., Schleicher, T., Schuler, D., Buchert, M., Blagoeva, D. (2016). Critical raw materials in lighting applications: substitution opportunities and implication on their demand, Phys. Status Solidi A, 216, pp. 2937-2946. DOI: 10.1002/pssa.201600594

[22] Smith, B.J., Eggert, R.G. (2016). Multifaceted material substitution: the case of NdFeB magnets, 2010-2015, JOM 2016, 7, pp. 1964-1971. DOI: 10.1007/s11837-016-1913-2

[23] Graedel, T.E. (2002). Material substitution: a resource supply perspective, Resour. Conserv. Recycl., 34, pp. 107-115. DOI: $10.1016 /$ S0921-3449(01)00097-0

[24] Ayres, R.U. (2007). On the practical limits to substitution, Ecol. Econ., 61, pp. 115-128. DOI: $10.1016 /$ j.ecolecon.2006.02.011

[25] Nakamura, E., Sato, K. (2011). Managing the scarcity of chemical elements, Nat. Mater., 10, pp. $158-161$. DOI: $10.1038 /$ nmat2969

[26] Powell, D. (2011). Sparing the rare earths: potential shortages of useful metals inspire scientists to seek alternatives for magnet technologies, Sci. News, 180, pp. 18-21. DOI: $10.1002 /$ scin.5591800522

[27] Gkanas, E.I., Bakouros, Y.L., and Makridis, S. S. (2015). "Substitutionability" of the Critical Raw Materials in Energy Applications: A Short Review and Perspectives, Mater. Sci.Eng. Adv. Res., 1(3), pp. 1-9. DOI: $10.24218 /$ msear.2015.11

[28] European Parliament, Substitutionability of Critical Raw Materials (Directorate General for Internal Policies, Brussels, 2012).

[29] Peck, D., Kandachar, P. and Tempelman, E. (2015). Critical materials from a product design perspective. Materials \& Design, 65, pp. 147-159. DOI: 10.1016/j.matdes.2014.08.042 
[30] Pavel, C.C.., Thiel, C., Degreif, S., Blagoeva, D., Buchert, M., Schuiler, D., Tzimas, E. (2017). Role of substitution in mitigating the supply pressure of rare earths in electric road transport applications. Sustainable Materials and Technologies, 12, pp. 62-72. DOI: 10.1016/j.susmat.2017.01.003

[31] Pavel, C.C., Arántegui, R.L., Marmier, A., Schuler, D., Tzimas, E., Buchert, M., Jenseit, W., Blagoeva, D. (2017). Substitution strategies for reducing the use of rare earths in wind turbines. Resources Policy, 52, 349-357. DOI: $10.1016 /$ j.resourpol.2017.04.010

[32] Rademaker, J.H., Kleijn, R., Yang, Y. (2013). Recycling as a strategy against rare earth element criticality: a systemic evaluation of the potential yield of NdFeB magnet recycling, Environ. Sci. Technol., 47, pp. 10129-10136. DOI: $10.1021 /$ es305007w

[33] Perez, J.P.H., Folens, K., Leus, K., Vanhaecke, F., Voort, P.V.D., Lainga, G.D. (2019). Progress in hydrometallurgical technologies to recover critical raw materials and precious metals from low-concentrated streams. Resources, Conservation and Recycling, 142, pp. 177-188. DOI: 10.1016/j.resconrec.2018.11.029

[34] Pavel, C.C., Marmier, A., Tzimas, E., Schleicher, T., Schüler, D., Buchert, M. and Blagoeva, D. (2016). Critical raw materials in lighting applications: Substitution opportunities and implication on their demand. Phys. Status Solidi A, 213(11), pp. 2937-2946. DOI: 10.1002/pssa.201600594

[35] EU Report of the Ad-hoc Working Group on defining critical raw materials, 2010, available on the Enterprise and Industry Directorate General. Web site https://ec.europa.eu/growth/tools-databases/eip-rawmaterials/en/community/document/critical-raw-materials-eu-report-ad-hoc-working-group-defining-critical-raw (accessed on 09.07.19)

[36] https:/ / epi.envirocenter.yale.edu (accessed 09.07.19)

[37] Chapman, A., Arendorf, J., Castella, T., Thompson, P and Willis, P. Study on Critical Raw Materials at EU Level, Final Report. Oakdene Hollins and Fraunhofer ISI. https: / /www.google.com/url?sa =t\&rct=j\&q=\&esrc=s\&source=web\&cd=1\&ved=2ahUKEwin $1 \mathrm{ZjxpJXhAhVa4KY}$ KHQVYD_0QFjAAegQIAhAC\&url=https $\% 3 \mathrm{~A} \% 2 \mathrm{~F} \% 2 \mathrm{Fec}$.europa.eu $\% 2 \mathrm{Fdocsroom} \% 2 \mathrm{Fdocuments} \% 2 \mathrm{~F} 5605 \% 2 \mathrm{Fa}$ ttachments $\% 2 \mathrm{~F} 1 \% 2$ Ftranslations $\% 2 \mathrm{Fen} \% 2$ Frenditions $\% 2$ Fnative\&usg=AOvVaw1JUpnQZTIwKEo38NyThHb2 (accessed 09.07.19)

[38] Study on the review of the list of Critical Raw Materials, Critical Raw Materials Factsheets. (2017). ISBN 978-92-7972119-9, DOI: $10.2873 / 398823$

[39] Ferro, P., Bonollo, F. (2019). Materials selection in a critical raw materials perspective. Materials and Design, 177, 107848. DOI: $10.1016 /$ j.matdes.2019.107848

[40] Ashby, M.F. (2000). Multi-objective optimization in material design and selection. Acta mater., 48, pp. 359-369. DOI: 10.1016/S1359-6454(99)00304-3. 